\title{
Xylometazoline nasal spray solution: novel composition used for treatment of nasal congestion
}

\begin{abstract}
The preliminary objective of the work is to develop the meter dose formulation of xylometazoline hydrochloride for enhanced effectiveness for nasal decongestion. The $3^{2}$ factorial design was utilized for development of the formulation, where sodium cholate (X1) and Polyethyleneglycol 400 concentration (X2) were independent factors. The optimized formulation composition consisted of $0.1 \mathrm{~g}$ sodium cholate and $1.5 \mathrm{ml}$ Polyethyleneglycol 400 independent varibales. The formulation was evaluated for solution parameters like assay, $\mathrm{pH}$, viscosity, \% diffusion, sterility, content uniformity, pump delivery, spray pattern, and weight loss. The percentage diffusion and viscosity was observed $81.00 \pm 2.00 \%$ and $24.33 \pm 0.57$ centipoise respectively. The meter dose nasal formulation provides alternative option for treatment of nasal decongestion which showed comparable results to marketed formulation.
\end{abstract}

Keywords: nasal decongestion, meter dose formulation, xylometazoline hydrochloride, polyethylene glycol 400 , sodium cholate
Volume 2 Issue 5 - 2018

\author{
Falgun Bhuva, Patel LD \\ Faculty of Pharmacy, Dharamsinh Desai University, India
}

Correspondence: Falgun Bhuva, Faculty of Pharmacy, Dharamsinh Desai University, India, Tel + 912-68 2-520-502, Email falgun_001@yahoo.co.in

Received: July 19, 2018| Published: September 05, 2018
Abbreviations: PEG400, polyethylene glycol 400; US, United States; Sodium CMC, Sodium carboxy methyl cellulose; USP, United States Pharmacopoeia; RH, Relative Humidity; Cp, centipoise

\section{Introduction}

The oral delivery of drug is the most common route for the drug administration owing to the advantage of ease of administration. The failure of adequate absorption through the gastrointestinal tract leads to explore the other alternate routes of drug delivery for desired therapeutic effect. For overcoming the limitations of conventional drug delivery system, the new drug delivery systems have been developed to suffice the need of healthcare profession. The pharmaceutical arena is constantly hunting for novel drug delivery system that can overwhelmed the existing drug delivery issues. ${ }^{1,2}$ Nose is one of the delicate organs of the body and due to which nasal drug delivery is challenge for the pharma formulator. Nasal route of administration would also thwart the presystemic metabolism thus intensifying the bioavailability of the drugs. ${ }^{3}$ The nasal drug delivery is the unique route for inhibiting drug degradation from first pass metabolism. Relatively large surface is available for the nasal route which is highly vascularized along with the leaky epithelium and may deliver the drug directly to brain. ${ }^{4}$ Nasal drug delivery system offers lucrative way of drug delivery for topical and systemic therapy. The systemic delivery of drug molecules by nasal route offers advantages like high permeability, vasculature and low enzymatic environment. Allergic rhinitis or sinusitis has one of the main indications as nasal congestion, which is related to enlargement of blood vessels and contracting of nasal passages. The continuous invent of new excipients, and in-situ gelling agent in pharma industry may increase the novel formulation of nasal drug delivery systems. ${ }^{5}$ Drug substance like xylometazoline, which is of imidazole class, act on alpha-adrenergic receptors of nasal mucosal arterioles leading to decrease of blood flow. Thus reducing the swelling of nasal turbinate's, relating to amplification of nasal lumen. ${ }^{6}$ Various excipients are used in novel drug delivery system with aim of taking specific roles in drug delivery system such as carriers, bioavailability enhancers, masking of taste, stabilizer, solubilizer etc. In recent days, various natural as well as synthetic polymers are widely used in nasal drug delivery. ${ }^{7}$ Xylometazoline solution is administered though nasal cavity, to achieve relief from nasal congestion, which is common to adults and children during cold and monsoon seasonal changes. The present work was carried out with thought to develop nasal spray of Xylometazoline hydrochloride by utilization of sodium cholate to enhance dug diffusion and PEG400 to impart viscosity to provide enhanced drug delivery. The meter dose spray formulation helps to deliver known amount of formulation.

\section{Materials and methods}

Xylometazoline $\mathrm{HCl}$ was procured from Anish Chemicals, Gujarat, India. Sodium cholate was purchased from National Chemicals Pvt. Ltd, Vadodara, India. PEG 400 sample was donated by Sigma Aldrich, USA. Methyl Paraben was obtained from S.D. Fine Chem. Ltd, Mumbai, India and Sodium carboxymethyl cellulose was obtained from Amar cellulose industries, Gujarat, India. The container closure system was obtained from Aptar Pharma, Mumbai, India Supplementary Table 2.

\section{Methods}

\section{Preparation of Xylometazoline $\mathrm{HCl}$ nasal solution:}

The drug substance contained nasal solution was developed by sequential mixing of various excipients as shown in Figure 1.

\section{Experimental design}

A 3 level 2 factors factorial design $\left(3^{2}\right)$ was adopted using concentration of sodium cholate (X1) and PEG 400 (X2) as independent variables for formulation development of xylometazoline solution. (Stat-Ease Design Expert ${ }^{\circledR}, \mathrm{v}$ 9). The levels of independent variables were designated as depicted in Table 1 and all the batches were formulated conferring to experimental design. (As per Table 2) The batches were then assessed for different parameters. 


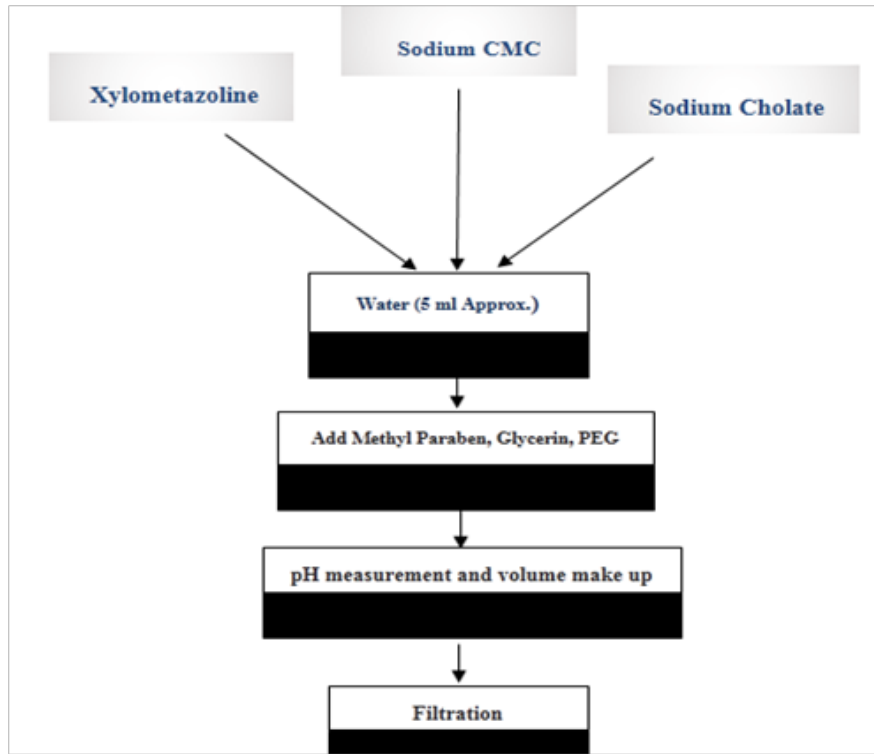

Figure I Method of preparation of nasal solution.

Table I Independent variables and their levels (Adult Dose Nasal Formulation)

\begin{tabular}{lll}
\hline \multirow{3}{*}{ Level } & \multicolumn{2}{l}{ Independent Variables } \\
\cline { 2 - 3 } & $\begin{array}{l}\text { XI=Content of Sodium } \\
\text { Cholate }(\mathbf{g})\end{array}$ & $\begin{array}{l}\text { X2=Content } \\
\text { of PEG 400 } \\
(\mathbf{m l})\end{array}$ \\
\hline$-($ low level) & 0.05 & $\mathrm{I}$ \\
0 (Medium Level) & 0.1 & 1.5 \\
+ I (High level) & 0.15 & 2 \\
\hline
\end{tabular}

Table 2 Composition of factorial design batches for adult dose nasal formulation

\begin{tabular}{lllll}
\hline Batch & $\begin{array}{l}\text { XI, Sodium Cholate } \\
\text { Content }(\mathbf{g m})\end{array}$ & $\begin{array}{l}\text { X2, PEG 400 } \\
\text { Content }(\mathbf{m l})\end{array}$ & XI & X2 \\
\hline FAI & 0.05 & $\mathrm{I}$ & -1 & -1 \\
FA2 & 0.1 & 1 & 0 & -1 \\
FA3 & 0.15 & $\mathrm{I}$ & 1 & -1 \\
FA4 & 0.05 & 1.5 & -1 & 0 \\
FA5 & 0.1 & 1.5 & 0 & 0 \\
FA6 & 0.15 & 1.5 & 1 & 0 \\
FA7 & 0.05 & 2 & -1 & 1 \\
FA8 & 0.1 & 2 & 0 & 1 \\
FA9 & 0.15 & 2 & 1 & 1 \\
\hline
\end{tabular}

* Each factorial design batch contained IOmg of xylometazoline, $0.0 \mathrm{lg}$ of $\mathrm{Na}$ CMC, $0.25 \mathrm{ml}$ of Glycerin, $0.0033 \mathrm{~g}$ Methyl Paraben, q.s. of $\mathrm{NaCl}$, and volume was made with purified water to $10 \mathrm{ml}$.

Equation 1 below demonstrations the polynomial equation for $3^{2}$ experimental design.

$$
Y i=\beta 0+\beta 1 \mathrm{X} 1+\beta 2 \mathrm{X} 2+\beta 12 \mathrm{X} 1 \mathrm{X} 2
$$

Where $\mathrm{Y}=$ dependent variable

$\beta 0=$ Intercept (arithmetic mean of all the batches) runs,

$\beta 1=$ estimated coefficient for the factor $\mathrm{X} 1$.

$\beta 2=$ Estimated coefficient for the factor X2

$\beta 12=$ Estimated coefficient of the interaction between $\mathrm{X} 1$ and $\mathrm{X} 2$

\section{Evaluation parameters of formulation}

\section{Appearance and clarity}

The formulated solutions were evaluated as in-house test for appearance (color) as well as their clarity. The color and clarity were visually examined against black and white surface in inspection booth Table $3 .^{8}$

\section{Drug content}

The drug substance in formulated nasal solution was evaluated by the method reported in the USP product monograph. ${ }^{9}$ The amount of xylometazoline hydrochloride in $\mathrm{mg}$ per $\mathrm{mL}$ of the nasal solution was calculated by the formula stated in equation 2 :

$$
\left(\frac{0.05 C}{V}\right)\left(\frac{A u}{A s}\right)
$$

Where, $\mathrm{C}$ is the concentration, in $\mu \mathrm{g}$ per $\mathrm{mL}$, in the standard preparation,

$\mathrm{V}$ is the volume, in $\mathrm{mL}$ of nasal solution,

$\mathrm{AU}$ is the absorbance of the solution for the assay preparation

AS is the absorbance of the solution from the standard preparation

Table 3 Results of responses of $3^{2}$ factorial design of xylometazoline nasal solution

\begin{tabular}{lll}
\hline $\begin{array}{l}\text { Parameter: } \\
\rightarrow \text { Batch* }\end{array}$ & $\begin{array}{l}\text { \% Diffusion at } \\
\text { I Ominutes [YI] }\end{array}$ & Viscosity (cP) [Y2] \\
\hline FAI & $75.33 \pm 0.57$ & $19.00 \pm 1.00$ \\
FA2 & $80.33 \pm 0.57$ & $20.33 \pm 0.57$ \\
FA3 & $81.00 \pm 1.73$ & $20.33 \pm 1.52$ \\
FA4 & $72.33 \pm 1.52$ & $22.33 \pm 1.15$ \\
FA5 & $81.00 \pm 2.00$ & $24.33 \pm 0.57$ \\
FA6 & $82.66 \pm 1.15$ & $23.33 \pm 0.57$ \\
FA7 & $70.33 \pm 0.57$ & $25.33 \pm 0.57$ \\
FA8 & $78.33 \pm 1.52$ & $25.66 \pm 0.57$ \\
FA9 & $90.66 \pm 0.57$ & $26.00 \pm 0.00$ \\
\hline
\end{tabular}

\section{$\mathrm{pH}$}

The $\mathrm{pH}$ of the nasal formulation have crucial role to endure normal physiological ciliary movement. All prepared formulations were measured in triplicate for $\mathrm{pH}$ using by digital $\mathrm{pH}$ meter and average value was considered. The model $\mathrm{pH}$ range of nasal formulations was in range of $6.5 \pm 0.3 .^{10-12}$ 


\section{Viscosity}

Viscosity has impact on the residence time of formulation, which is directly related to rate of drug absorption through nasal mucosa. The viscosity of the prepared solution was measured through Brookfield Viscometer (Spindle no S18 at 100rpm) (Brookfield Viscometer, Model no LVDL-2T, Dolphine instrument, Mumbai). ${ }^{8}$

\section{Spray content uniformity}

The spray content uniformity as important parameter for nasal spray, was studied to investigate the spray discharged from the nosepiece for the drug substance content. The examination was carried out for multiple spray form single container and in different container for the same. This test will determine an overall performance evaluation of the formulated batch, which will assess the pump selection. The acceptance criteria was nominated as the amount of drug substance not outside of 80-120percent of label claim for more than 1 of 10containers, none of the determinations is outside of 75-125percent of the label claim, and the mean is not outside of $85-115$ percent of label claim. ${ }^{13,14}$

\section{Pump delivery}

The pump delivery as well as spray content uniformity are related constraints implicating substantial effect on the product enactment. The formulation was evaluated for pump-to-pump reproducibility and the metering capability of the pump. The formulation was filled into the container closure, which was further actuated for 10times in a pre-weighed bottle. The weight of the bottle was reweighed after 10 actuations and the difference was calculated. ${ }^{8}$

\section{Spray pattern}

The charactarization of spray is the pathway through which the performance of the pump and the nozzle of container closure system need to be evaluated. In the evaluation of the spray pattern, the spray distance between the nose- piece and the collection surface, orientation of the nose-piece, and visualization procedure are specified. Spray Pattern of prepared nasal spray formulation was measured by the SprayVIEW system (Proveris Scientific Cooperation, USA) furnished with the SprayVIEW automated pump actuation system. The parameters of spray pattern assessment are height at $30 \mathrm{~mm}$, evacuation time 15000 millisecond, inclination as $65.4^{\circ}$ and summation mode as automatic. . $^{13,14}$

\section{Weight loss}

The regulatory guildeline published by EMEA and FDA for nasal products indicated that the weight loss is critical parameters that determines the product performance and stability. Inverted and Horizontal positions (i.e. both the orientations plays significant role in weight loss) were kept for the drug product storage to assess this characteristic. The net content of formulation in the container closure system was determined as per USP chapter $<755>$ and it is essentially to be in accordance with the predefined specification., ${ }^{9,13,15}$

\section{Priming and repriming}

The first priming essentially to demonstrate the minimum amount of drug released from the product, while repriming shows the ability of product to delivery same amount of drug content after storage of product. The length of storage for conducting the study is defined as 5, 10 and 30days. The number of actuations are determined that are required for priming until the subsequent doses meet the specification limits ( $80-120 \%$ label claim). The number of actuations are determined that are required for re-priming up to the subsequent doses meets the specification limits. ${ }^{9,14}$

\section{In-vitro diffusion study}

The In-vitro diffusion study was performed using the Franz diffusion cell. The recently isolated sheep nasal mucosa, was obtained from a local slaughter house. The nasal mucosa was seperated and sunken in phosphate buffer (along with aeration) for safeguarding the tissue. Thel mucosa was attached on diffusion chamber with the mucosal side facing the donor phase. The doner medium comprised of formulation, while the receptor medium comprised of phosphate buffer. The temperature of the medium was maintained at $37^{\circ} \mathrm{C} \pm 1^{\circ} \mathrm{C}$. The receptor medium was refilled with the equivalent volume of the fresh solution as the samples withdrawn. The samples were then analyzed spectrophotometrically at a wavelength of $265 \mathrm{~nm}$ against blank. The obtained results were compared with the current marketed formulation Otrivin ${ }^{\circledR}$ (Novartis). ${ }^{16,17,18}$

\section{Droplet size distribution}

The in-vivo deposition of the formulation in cavity is affected by droplet size analysis of the formulation spray. The major factor that influences the droplet size is the delivery device and the formulation. The USFDA guideline for nasal aqueous spray formulation states that there must be appropriate control for droplet size distribution of the delivered plume. The droplet size distribution can be controlled in terms of D10, D50, and D90 by utilization of laser diffraction. ${ }^{19,20}$

\section{Sterility}

Sterility is one of the most mandetory requirement for nasal preparation. The support for the test is that at fortunate conditions (temperature as well as nutrition) the microorganisms will grow, which can be recognized by turbidity in the medium. The method used was as per USP general chapter sterilitiy tests $<71>{ }^{21}$

\section{Stability study}

The stability studies was executed for long term study at $25 \pm 2{ }^{\circ} \mathrm{C} / 60 \pm 5 \% \mathrm{RH}$ in the period of $0,3,6,9$ and 12 months, while for accelerated study was evaluated at $40 \pm 2^{\circ} \mathrm{C} / 75 \pm 5 \% \mathrm{RH}$ in the period of 0,3 and 6 months. ${ }^{22}$

\section{Results and discussion}

\section{Preliminary trials and composition of nasal formulation}

The preliminary formulation trials were designed for the selection of surfactant concentration, and co-solvent amount. The preliminary parameters like clarity, $\mathrm{pH}$, drug content, $\%$ diffusion at 10 minutes and viscosity were optimized by varying one parameter at a time, while keeping the others constant, so that the effect of varied parameter could be evaluated. Eskandar Moghimipour et al. investigated bile salts as absorption improving agents for nasal delivery. ${ }^{23}$ The bile salt absorption improvement pathway consist of membrane protein or lipid extraction, fluidization of membrane, reverse micelle production within membrane thus generating aqueous networks. Higher concentrations of bile salts, points towards membrane lipids extraction forming micelles, augmenting transcellular movement. Sodium Cholate is an exceptional bile salt, which is widely considered candidate of bile salt family. Polyethylene glycol (PEG) is a polymer of prime for 
drug delivery. With various preliminary trials the concentration range for sodium cholate was finalized as $0.05 \mathrm{gm}-0.15 \mathrm{gm}$, while that of PEG400 as $1.0 \mathrm{ml}-2.0 \mathrm{ml}$ Figure 4.

\section{Experimental design}

Nasal Solution was developed by utilizing $3^{2}$ factorial design. As per the design layout, all the nine possible experimental trials were performed. These batches were assessed using polynomial equation

$$
\% \text { Diff. at } 10 \operatorname{mins}(Y 1)=79.4444+6.0555 * \mathrm{X} 1+0.4444 * \mathrm{X} 2+3.6667 * \mathrm{X} 1 * \mathrm{X} 2-1.1667(X 1) 2+0.6667(X 2) 2
$$

Among the independent variables, X1 had more positive effect $(\beta 1=6.0555)$ on $\%$ diffusion at 10 minutes. The $\mathrm{X} 2$ variable had very minor effect $(\beta 2=0.4444)$, while the interaction between $\mathrm{X} 1$ and $\mathrm{X} 2$ showed positive impact on $\%$ diffusion at 10 minutes $(\beta 12=3.6666)$. Sodium cholate as an excipient exhibited prominent impact on $\%$ diffusion at ten minutes. The data of model summary statistic for $\%$ diffusion at 10minutes (Y1) clearly suggest the quadratic model

Table 4 ANOVA for response diffusion at 10minutes of design. Moreover, two check point baches were confirmatory for validation of design of experiment. The assessment tests consisted for appearance, $\mathrm{pH}$, viscosity, assay and \% diffusion at 10 minutes factorial batches. However, by shifting the level of independent variables sodium cholate (X1) and PEG 400 (X2), the \% diffusion at 10 minutes and viscosity displayed differences, henceforward they were defined as dependent parameters. The polynomial equation was obtained by regression analysis of the results of \% diffusion at 10 minutes for $3^{2}$ factorial design batches by equation 3 : shows better suitability as compared to other statistic models. The Table 4 displays the independent variables impact on the percentage diffusion at 10 minutes. The data obtained reveals that the $\mathrm{p}$-value $<0.05$ stating that the factor has significant impact on dependent parameter. Hence conclusion can be derived that the both independent variables (Sodium cholate and PEG 400) have substantial impact on diffusion rate on formulation.

\begin{tabular}{lllllll}
\hline Source & Sum of squares & df & Mean square & F value & P-value prob $>$ F & Coefficient \\
\hline Model & 278.59 & 5 & 55.71 & 11.87 & 0.0343 (significant) & - \\
Intercept $\left[\left(\beta_{0}\right)\right]$ & - & - & - & - & - & 79.4444 \\
Sodium cholate & 219.98 & $\mathrm{I}$ & 219.98 & 46.85 & 0.0064 & 6.0555 \\
{$\left[\left(\beta_{1}\right)\right]$} & 1.18 & $\mathrm{I}$ & 1.18 & 0.25 & 0.6498 & 0.4444 \\
PEG $400\left[\left(\beta_{2}\right)\right]$ & 53.73 & $\mathrm{I}$ & 53.73 & 11.44 & 0.0429 & 3.6667 \\
{$\left[\left(\beta_{12}\right)\right]$} & 2.73 & $\mathrm{I}$ & 2.73 & 0.58 & 0.5016 & -1.1667 \\
{$\left[(\beta \mathrm{I})^{2}\right]$} & 0.89 & $\mathrm{I}$ & 0.89 & 0.19 & 0.6927 & 0.6667 \\
{$\left[(\beta 2)^{2}\right]$} & 14.07 & 3 & 4.69 & - & - & - \\
Residual & 292.66 & 8 & - & - & - & - \\
Cor Total & & & & & \\
\hline
\end{tabular}

The polynomial equation 4 was obtained by regression analysis of the results of viscosity for $3^{2}$ factorial design batches as below:

$$
\operatorname{Viscosity}(Y 2)=23.8148+0.5000 * \mathrm{X} 1+2.8889 * \mathrm{X} 2-0.1667 * X 1 * X 2-0.7222(X 1) 2-0.5556(X 2) 2
$$

It is also observed that sodium cholate (X1) and PEG 400 (X2) substantially impact the viscosity of formulation. The quadratic model shows the enhanced fitting related to other models. The influences of independent factors were as evaluated as displayed in Table 5. The independent variable $\mathrm{X} 2$, had prominent positive effect $(\beta 2=2.8889)$ on viscosity, while the $\mathrm{X} 1$ variable had very minor impact $(\beta 1=$ $0.5000)$ on viscosity. The changing of factor (PEG 400) X2 from -1 to +1 showed the viscosity change from $20 \mathrm{cp}$ to $25 \mathrm{cps}$. The creation was performed for contour and surface plot for viscosity. The Table

Table 5 ANOVA for response viscosity

\begin{tabular}{lllllll}
\hline Source & $\begin{array}{l}\text { Sum of } \\
\text { squares }\end{array}$ & df & Mean square & F value & p-value prob>F & Coefficient \\
\hline Model & 53.34 & 5 & 10.66 & 42.5 & 0.0055 (significant) & - \\
Intercept $\left[\left(\beta_{0}\right)\right]$ & - & - & - & - & - & 23.8148 \\
Sodium cholate $\left[\left(\beta_{1}\right)\right]$ & 1.5 & $\mathrm{I}$ & 1.5 & 5.94 & 0.0928 & 0.5 \\
PEG 400[( $\left.\left.\beta_{2}\right)\right]$ & 50.05 & $\mathrm{I}$ & 50.05 & 198.1 & 0.0008 & 2.8889 \\
{$\left[\left(\beta_{12}\right)\right]$} & 0.11 & $\mathrm{I}$ & 0.11 & 0.43 & 0.5584 & -0.1667 \\
\hline
\end{tabular}

6 displayed the percentage error observed between the experimental value and the predicted value of various experimental batches. The $\%$ bias value of diffusion at 10 minutes was found in the range of $-4.83 \%$ to $4.12 \%$ and the $\%$ bias value for viscosity was found in the range of $-1.87 \%$ to $2.13 \%$. The percentage bias/error for both the variables were found below $5 \%$, which endorsed the model selected was successfull to predict the response of the experimental design. The summary of the results of regression analysis of batches of xylometazoline nasal solution for full and reduced model was provided in Table 7 . 


\begin{tabular}{llllll} 
Table Continued & Sum of & & & & \\
Source & squares & df & Mean square & F value & p-value prob>F \\
\hline$\left[(\beta I)^{2}\right]$ & 1.04 & $\mathrm{I}$ & 1.04 & 4.1 & 0.1359 \\
{$\left[(\beta 2)^{2}\right]$} & 0.62 & $\mathrm{I}$ & 0.62 & 2.44 & 0.2163 \\
Residual & 0.75 & 3 & 0.25 & - & - \\
Cor Total & 54.09 & 8 & - & - & - \\
\hline
\end{tabular}

Table 6 Percentage bias for experimental batches

\begin{tabular}{|c|c|c|c|c|c|c|c|c|}
\hline $\begin{array}{l}\text { Batch } \\
\text { No. }\end{array}$ & $\begin{array}{l}\text { Composition of } \\
\text { sodium cholate }\end{array}$ & $\begin{array}{l}\text { Composition } \\
\text { of PEG }\end{array}$ & $\begin{array}{l}\text { Calculated } \\
\text { value of diff. }\end{array}$ & $\begin{array}{l}\text { Exp } \\
\text { value of } \\
\text { diff }\end{array}$ & $\begin{array}{l}\% \text { Bias } \\
\text { for } \\
\text { diff. }\end{array}$ & $\begin{array}{l}\text { Calculated } \\
\text { value of vsc. }\end{array}$ & $\begin{array}{l}\text { Exp } \\
\text { value of } \\
\text { vis. }\end{array}$ & $\begin{array}{l}\% \text { Bias } \\
\text { for } \\
\text { visc. }\end{array}$ \\
\hline FAI & -1 & -1 & 78.44 & 75.33 & 4.12 & 18.98 & 19 & 0.1 \\
\hline FA2 & 0 & -1 & 79.66 & 80.33 & 0.83 & 20.37 & 20.33 & -0.15 \\
\hline FA3 & I & -1 & 83.22 & 81 & 2.74 & 20.31 & 20.31 & 0.09 \\
\hline FA4 & -1 & 0 & 74.55 & 72.33 & 0.15 & 22.59 & 22.33 & -1.16 \\
\hline FA5 & 0 & 0 & 79.44 & 81 & 3.06 & 23.81 & 24.33 & 2.13 \\
\hline FA6 & 1 & 0 & 86.66 & 82.66 & -4.83 & 23.59 & 23.33 & $-|| 1$. \\
\hline FA7 & -1 & I & 71.99 & 70.33 & 2.37 & 25.09 & 25.33 & 0.98 \\
\hline FA8 & 0 & 1 & 80.55 & 78.33 & -2.83 & 26.14 & 25.66 & -1.87 \\
\hline FA9 & I & I & 91.44 & 90.66 & -0.86 & 25.75 & 26 & 0.96 \\
\hline
\end{tabular}

Table 7 Summary of the results of regression analysis of batches of xylometazoline nasal solution for factorial design and constraints for selection of optimized formulation

\begin{tabular}{lllllllll}
\hline Response & Model & $\mathbf{\beta 0}$ & $\boldsymbol{\beta 1}$ & $\mathbf{B 2}$ & $\boldsymbol{\beta}$ I & $\boldsymbol{\beta 2 2}$ & $\boldsymbol{\beta 1 2}$ & $\mathbf{R 2}$ \\
\hline \multirow{2}{*}{ \% Diff. at I0 mins. } & Full & 79.4444 & 6.0556 & 0.4444 & -1.1667 & 0.6667 & 3.6667 & 0.9518 \\
& Reduced & 79.1111 & 6.0556 & 0.4444 & - & - & 3.6667 & 0.9395 \\
Viscosity & Full & 23.8148 & 0.5 & 2.8889 & -0.7222 & -0.5556 & -0.1667 & 0.9859 \\
& Reduced & 22.9629 & 0.5 & 2.8889 & - & - & - & 0.9533
\end{tabular}

\section{Constraints for selection of optimized formulation}

$\begin{array}{ll}\text { Diffusion } & \text { Limit } \\ \text { Diffusion at } 2.5 \text { minutes } & \text { \% diffusion between } 16 \text { to } 18 \% \\ \text { Diffusion at } 5 \text { minutes } & \text { \% diffusion between } 35 \text { to } 40 \% \\ \text { Diffusion at } 10 \text { minutes } & \text { \% diffusion between } 80 \text { to } 85 \% \\ \text { Diffusion at } 15 \text { minutes } & \text { \% diffusion between } 90 \text { to } 95 \%\end{array}$




\section{Optimization of experimental design}

The design of experimental model was supplementarily authenticated by two check point batches. The verification for $\%$ diffusion and viscosity of checkpoint batches was accomplished by utilizing mathematics equation $(3,4)$. The Table 8 portrays the results for check point batches for $\%$ diffusion at 10 minutes and viscosity. The contour and surface response plots were as shown in the Figure 2. The optimization nasal solution was selected on the basis of the arbitrary constraints for the factorial design batches stated in Table 7. The optimized formulation contained sodium cholate $0.12 \mathrm{~g}(1.2$ $\% \mathrm{w} / \mathrm{v})$ and PEG $4001.5 \mathrm{~mL}(15 \% \mathrm{v} / \mathrm{v})$ displayed in Table 9. This formulation (batch FA5) displayed values for \% diffusion at $10 \mathrm{~min}$ and viscosity are $81,00 \%$ and $24.33 \mathrm{cps}$ respectively. The comparision of in- vitro diffusion results between otrivin and batch FA5 is revealed in Figure 4, indicating that the optimized formulation demonstrating comparable \% diffusion at 10minutes Supplimentary Table 2.

Table 8 Check point batches results for dependent variables with \% bias

\begin{tabular}{lllllllll}
\hline Sr. & \multirow{2}{*}{$\begin{array}{l}\text { No. } \\
\text { Nonc. of sodium cholate }\end{array}$} & \multicolumn{2}{l}{$\begin{array}{l}\text { Conc. of PEG } \\
\mathbf{4 0 0}\end{array}$} & \multicolumn{2}{c}{ Diffusion at I Omin (\%) } & \multicolumn{3}{c}{ Viscosity (cp) } \\
\cline { 3 - 9 } & & & Actual & Predicted & \% Bias & Actual & Predicted & $\%$ Bias \\
\hline 1 & -0.4 & -0.2 & 77.3 & 77.43 & -0.16 & 22.6 & 22.88 & -1.23 \\
2 & 0.4 & -0.6 & 81.3 & 81.14 & 0.19 & 21.3 & 22 & -3.28 \\
\hline
\end{tabular}

Table 9 Results of optimized batch composition (FA5) and arket product

\begin{tabular}{|c|c|c|}
\hline \multicolumn{2}{|l|}{ Ingredients } & Composition \\
\hline \multicolumn{2}{|c|}{ Xylometazoline $\mathrm{HCl}$} & $10 \mathrm{mg}$ \\
\hline \multicolumn{2}{|l|}{ Sodium Cholate } & $0.1 \mathrm{~g}$ \\
\hline \multicolumn{2}{|l|}{ PEG400 } & $1.5 \mathrm{ml}$ \\
\hline \multicolumn{2}{|l|}{ Sodium CMC } & $0.01 \mathrm{~g}$ \\
\hline \multicolumn{2}{|l|}{ Glycerin } & $0.25 \mathrm{ml}$ \\
\hline \multicolumn{2}{|l|}{ Methyl Paraben } & $0.0033 \mathrm{~g}$ \\
\hline \multicolumn{2}{|l|}{ Ingredients } & Composition \\
\hline \multicolumn{2}{|l|}{$\mathrm{NaCl}$} & qs \\
\hline \multicolumn{2}{|l|}{ Purified Water } & qs to $10 \mathrm{ml}$ \\
\hline Parameters & Market product (B. No: 30848M) & Optimized batch (B. No: FA5) \\
\hline Assay ( $\%$ w/w) & $98.74 \pm 0.83$ & $99.69 \pm 0.38$ \\
\hline Clarity & Clear Solution & Clear Solution \\
\hline $\mathrm{pH}$ of solution & $6.50 \pm 0.0$ & $6.50 \pm 0.0$ \\
\hline Drug diffusion & $74.3 \pm 0.57$ & $81.00 \pm 2.00$ \\
\hline Viscosity & $5.33 \pm 0.57$ & $24.33 \pm 0.57$ \\
\hline
\end{tabular}

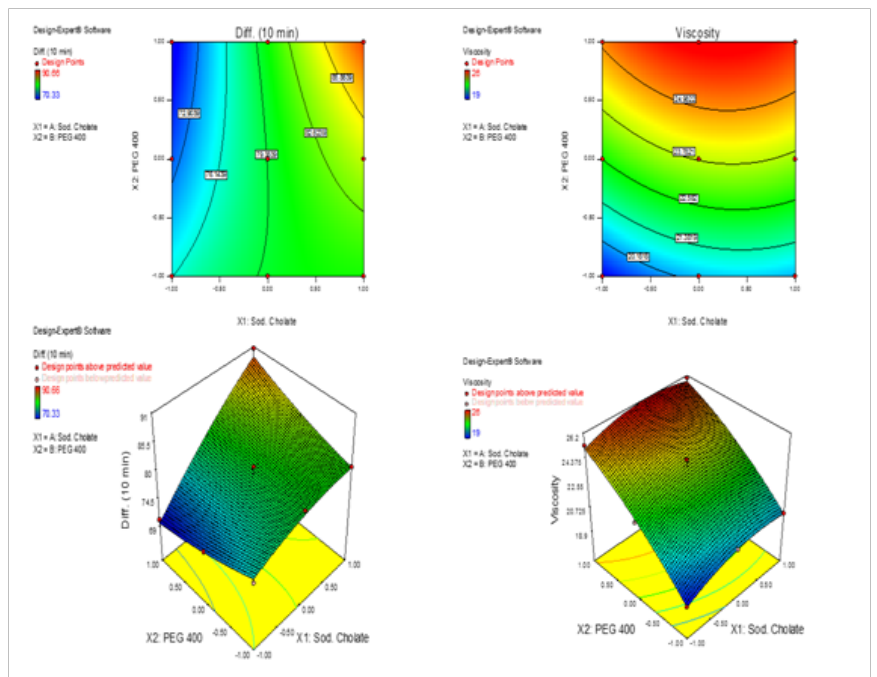

Figure 2 Contour and Response Surfacr Plots for \% Diffusion and viscosity. 


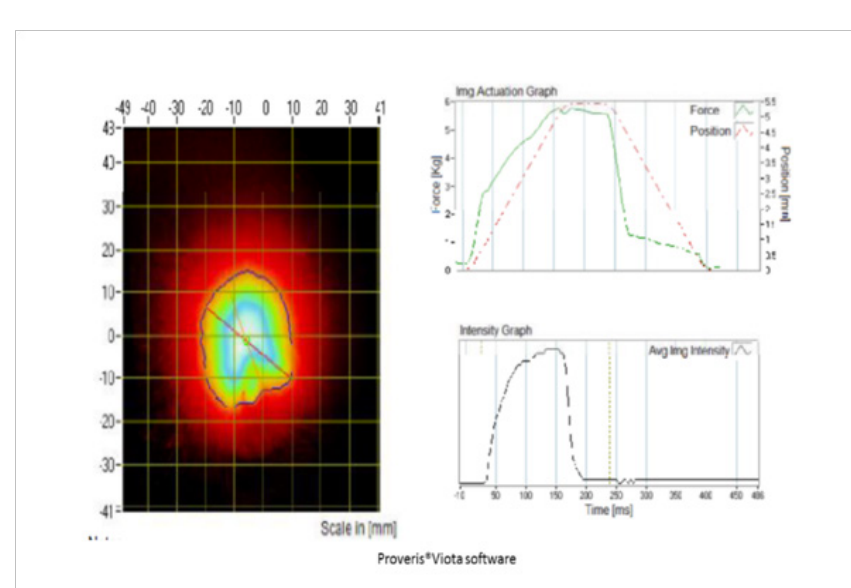

Figure 3 Spray pattern, Image Actuation Graph and Intensity Graph of formulation.

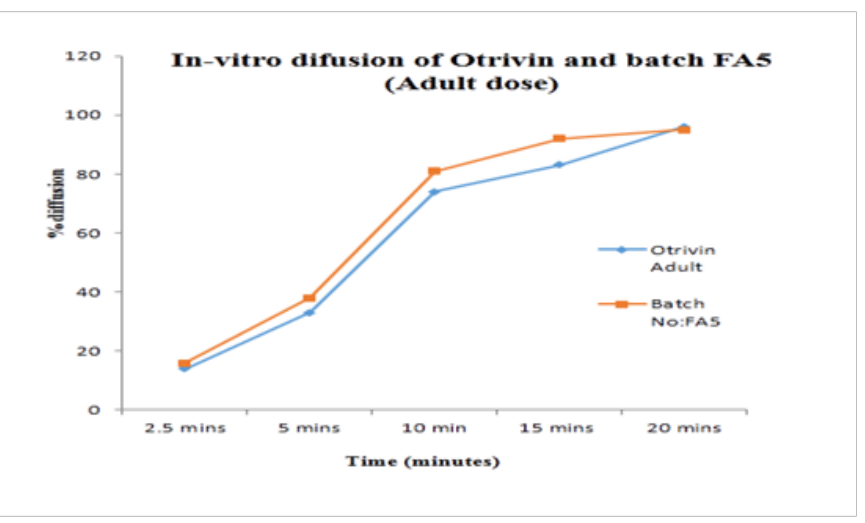

Figure 4 In-vitro diffusion comparison of marketed formulation and optimized batch.

\section{Other evaluation parameters}

$\mathrm{pH}$

The formulation $\mathrm{pH}$ for factorial design batches was found in the range of $6.50 \pm 0.3$ showing better compatibility at the delivery site.

\section{Spray content uniformity}

The formulations must be assessed in its relationships of emitted dose content uniformity. The performance evaluation of system by assessing the formulation, valve and the actuator is observed by Regulatory bodies like FDA as the control of content uniformity. The Table 10 data indicated the drug substance content sprayed within same container and among the different containers. The results are in the range of $94-102 \%$, which passes the test bestowing to guidelines for nasal products.

\section{Pump delivery}

The apposite performance from pump is fundamentally required for accurate delivery of drug to targeted part. The specific dose constantly is delivered by the pump is assurance by this test. The paking material along with the pump was acquired from Aptar Pharma. The initial weight of filled nasal spray was $15 \mathrm{~g}$. The final weight of spray system was found the $15 \mathrm{~g}$ after 10 actuations, with the actuation volume for each spray as $100 \mu l$. The data indicated that the packaging system was able to delivery precise amount of the drug substance.

\section{Spray pattern}

The pumping performance can be estimated with the help of spray pattern test. This test could be impacted by factors such as the size and shape of the nozzle of pump, the design of the pump, the formulation characteristics etc. The ovality attained was 1.217 , while perimeter and area were found to be $104.56 \mathrm{~mm}$ and $791.5 \mathrm{~mm}^{2}$ respectively. Image actuation graph, along with intensity graph for the formulation are as presented in Figure 3. The figure endorses that the pump delivered the required medication appropriately without any concerns.

\section{Weight loss}

The FDA guideline for nasal sprays clearly state that the weight loss study must be performed considering the worst case scenario for orientation of container closure. Thus the formulation was stored in both i.e. inverted and horizontal position. Net content in the product container closure was checked initially, while weight loss study was performed for stability time points of 3 and 6months. As shown in Table 10, the results indicated that there was no any change for weight loss study demonstrating the reliability of packaging components.

Table 10 Drug substance content among different containers and same containers

\begin{tabular}{lllll}
\hline Sr. No & Batch no & CI* & C2* & C3* \\
\hline I & FA5 & $96 \%$ & $94 \%$ & $101 \%$ \\
\multicolumn{5}{l}{ Drug substance content among same containers } \\
Sr. No & Batch No & SI\# & S2\# & S3\# \\
I & FA5 & $98 \%$ & $97 \%$ & $102 \%$ \\
\hline
\end{tabular}

* indicates different containers labelled $\mathrm{Cl}, \mathrm{C} 2$ and $\mathrm{C} 3$ used for Spray content test.

\# indicates different sprays (SI, S2 and S3)

\section{Priming and repriming study \\ Priming study}

These studies were executed to support the number of actuations to be suggested which essentially to be fired to discarded prior to the end user using the product for the first time and subsequent use afterwards. The priming study was performed on formulation nasal spray and the results obtained were $97.6 \%$ and $98.5 \%$ respectively for first actuation. This study referenced that only one actuation requirement as priming since the results obtained were higher than 95\% Table 11 .

\section{Repriming study}

Repriming study results at 5 days, 10 days and 30 days are as shown in Table 12. The least value for repriming within 5, 10 and 30days was obtained to be $95.4 \%$ while the extreme value acquired was $100.2 \%$. It was concluded that one actuation was satisfactory for repriming.

\section{Droplet size dstribution}

The droplet size study was performed based on laser diffraction method. The instrument used was automatatic nasal actuator (Malvern Instruments,UK) further assembled onto spraytech. The droplet size distribution was carried out for five containers labelled $\mathrm{C} 1$ to $\mathrm{C} 5$, where each container was actuated at $6 \mathrm{~cm}$ distance from orifice of 
actuator. Single scan was used for performing droplet size distribution at fully developed spray stable phase. The results of median droplet size (D50) mean from $6 \mathrm{~cm}$ actuation distance are shown in Table 13.
The D50 value was obatined in the range of 52.42 to $66.60 \mu \mathrm{m}$ for different containers.

Table II Inverted and horizontal position for net content and weight loss evaluation

\begin{tabular}{llllll}
\hline Sr. No & Batch No & Container & Initial Wt & Wt after $\mathbf{3}$ months & Wt after $\mathbf{6}$ months \\
\hline I & FA5 & 1 & $15 \mathrm{gms}$ & $15 \mathrm{gms}$ & $15 \mathrm{gms}$ \\
2 & FA5 & 2 & $15 \mathrm{gms}$ & $15 \mathrm{gms}$ & $15 \mathrm{gms}$ \\
\multicolumn{1}{l}{ Horizontal position for net content and weight loss evaluation } & $15 \mathrm{gms}$ \\
\hline & FA5 & 1 & $15 \mathrm{gms}$ & $15 \mathrm{gms}$ & $15 \mathrm{gms}$ \\
\hline
\end{tabular}

Table 12 Repriming study for 5, 10 and 30 days

\begin{tabular}{lllll}
\hline Cont. No. & Duration & Repriming & No of actuations & Assay results \\
\hline I & 5d & Yes & I & $95.40 \%$ \\
2 & 5d & Yes & I & $99.70 \%$ \\
Repriming study for 10 days & & & \\
I & I0d & Yes & I & $100.20 \%$ \\
2 & Yes & I & $96.80 \%$ \\
Repriming study for 30days & & & \\
I & 30 d & Yes & I & $98.50 \%$ \\
2 & 30 d & Yes & I & $99.40 \%$ \\
\hline
\end{tabular}

Table 13 Results for Droplet size $\left(D_{50}\right)$ distribution

\begin{tabular}{ll}
\hline Container number & D50 value $(\mu \mathrm{m})$ \\
\hline 1 & $66.60 \pm 3.78$ \\
2 & $61.63 \pm 4.72$ \\
3 & $52.42 \pm 2.97$ \\
4 & $56.59 \pm 3.19$ \\
5 & $57.77 \pm 3.63$
\end{tabular}

\section{Sterility}

The sterility of the optimized formulation (batch number: FA5) was carried out according to USP criteria. The sterility test showed no microbial growth, which indicated that the formulation was sterile.

\section{Stability studies}

The stability of optimized nasal formulation (Batch FA5) was conceded at $25 \pm 2^{\circ} \mathrm{C} / 60 \pm 5 \% \mathrm{RH}$ for 12 months and accelerated condition studies were performed at $40 \pm 2^{\circ} \mathrm{C} / 75 \pm 5 \%$ RH for 6 months. The results were displayed in Table 14. All the results related to stability studies were found well within the acceptance criteria without any significant change comparing initial results. During and at the completion of the stability study (accelerated and long term), the Batch number FA5 disclosed drug content comparable to original results. Batch number FA5 also demonstrated the sensible appearance, $\mathrm{pH}$, in vitro diffusion, viscosity and sterility at the completion of the stability study.

\section{Conclusion}

The study evidenced utilization of factorial design pathway towards development of solution formulation. The pre- formulation study was supported for drug substance xylometazoline. The drugexcipient compatibility study designated no interaction between xylometazoline and the excipients. The $3^{2}$ full factorial design was utilized, where sodium cholate (X1) and PEG400 (X2) were earmarked as independent factors. The formulation was evaluated for solution parameters like drug content, $\mathrm{pH}$, viscosity, \% diffusion, sterility, spray content uniformity, pump delivery, spray pattern, and weight loss. The percentage diffusion and viscosity was observed $81.00 \pm 2.00 \%$ and $24.33 \pm 0.57$ centipoise respectively. For spray pattern, the ovality attained was 1.217 , while perimeter and area were found to be $104.56 \mathrm{~mm}$ and $791.5 \mathrm{~mm}^{2}$ respectively. The D50 value was obatined in the range of 52.42 to $66.60 \mu \mathrm{m}$ for different containers. The formulation was evaluated for its stability up to 12 months at long term conditions and found satisfactory. The formulated batch FA5 showed comparable performance for in-vitro drug release with marketed product thus providing auxiliary option for treatment of nasal congestion Figure 5. 
Table I4 Stability study results for optimized formulation

\begin{tabular}{llllll}
\hline Specifications & Initial $(\mathbf{O m})$ & At 3months & At 6months & At 9months & At I 2months \\
\hline Appearance & Clear solution & Clear solution & Clear solution & Clear solution & Clear solution \\
$\mathrm{pH}$ & $6.50 \pm 0.0$ & $6.40 \pm 0.0$ & $6.5 \pm 0.0$ & $6.53 \pm 0.05$ & $6.50 \pm 0.0$ \\
Viscosity (cP) & $99.7 \pm 0.38$ & $99.3 \pm 0.75$ & $99.40 \pm 0.76$ & $99.07 \pm 1.23$ & $98.60 \pm 0.83$ \\
Assay (\%) & $81.00 \pm 2.00$ & $81.66 \pm 1.52$ & $80.66 \pm 1.52$ & $83.33 \pm 0.57$ & $82.66 \pm 0.57$ \\
$\%$ diffusion & $24.33 \pm 0.57$ & $24.33 \pm 0.57$ & $23.33 \pm 0.57$ & $24.33 \pm 0.57$ & $24.00 \pm 1.00$ \\
Net content* & $10 \mathrm{ml}$ & - & - & - & $10 \mathrm{ml}$ \\
Sterility* & meets the requirement & - & - & meets the requirement \\
\hline
\end{tabular}

Long Term stability study results at $25 \pm 2^{\circ} \mathrm{C} / 60 \pm 5 \% \mathrm{RH}$

Specifications Initial $(0 \mathrm{~m}) \quad$ At 3months At 6months At 9months At I2months

\begin{tabular}{|c|c|c|c|}
\hline \multicolumn{4}{|c|}{ Accelerated stability study results at $40 \pm 2^{\circ} \mathrm{Cl} 75 \pm 5 \% \mathrm{RH}$} \\
\hline Specifications & Initial $(0 \mathrm{~m})$ & At 3months & At 6 months \\
\hline Appearance & Clear solution & Clear solution & Clear solution \\
\hline $\mathrm{pH}$ & $6.50 \pm 0.0$ & $6.53 \pm 0.05$ & $6.50 \pm 0.0$ \\
\hline Viscosity (cp) & $99.7 \pm 0.38$ & $100.44 \pm 0.46$ & $99.16 \pm 0.35$ \\
\hline Assay (\%) & $81.00 \pm 2.00$ & $80.66 \pm 0.57$ & $83.33 \pm 1.15$ \\
\hline$\%$ diffusion & $24.33 \pm 0.57$ & $24.66 \pm 0.57$ & $24.33 \pm 0.57$ \\
\hline Net content* & IOml & - & $10 \mathrm{ml}$ \\
\hline Sterility* & meets the requirement & - & meets the requirement \\
\hline
\end{tabular}

*These tests were performed initially and at end point.

\section{Acknowledgements}

We are thankful to those who have directly or indirectly helped us in the research and make it possible. We are extremely thankful to Anish chemicals, Gujarat for providing drug substance xylometazoline hydrochloride. We are also extremely thankful to Aptar pharma for providing container closure system.

\section{Conflict of interests}

The author declares that there is no conflict of interest.

\section{References}

1) Rene B, Erich Pfeiffer. Drug Delivery: Nasal Route. Encyclopaedia of pharmaceutical technology. 2006;1201-1208.

2) Saudagar RB, Khandbhale SV. Formulation development and evaluation of nasal insitu gel of fluticasone propionate. International Journal of Current pharmaceutical Research. 2017;9(5):45-54.

3) Pozolli M, Rogueda P, Zhu B, et al. Dry powder nasal drug delivery: challenges, opportunity and a study of commercial Teijin pulvizer rhinocort device and formulation. Drug Development and Industrial pharmacy. 2016;42(10):912-924.

4) Fatouh AM, Elshafeey AH, Abdelbary A. Intranasal Agomalatine solid lipid nano particles to enhance brain delivery: formulatiol, optimization and in-vivo pharmacokinetics. Drug Design Development and Therapy. 2017;11:1815-1825.

5) Khan AR, Lui M, Khan MW, et al. Progress in brain targetting drug delivery system by nasal route. Journal of Controlled Release. 2017;268:364-389.

6) Corboz MR, Rivelli MA, Mingo GG, et al. Mechanism of decongestant activity of alpha 2-adrenoceptor agonists. Pulmonary Pharmacology and therapeutics. 2008;21(3):449-454.

7) Hasçiçek C, Gonul N, Erk N. Mucoadhesive microspheres containing gentamicin sulfate for nasal administration: preparation and in vitro characterization. Farmaco. 2003;58(1):11-16.

8) Michael S, Ferguson BJ, Len F. Epedemeology and burden of nasal congestion. International Journal of General Medicine. 2010;3:37-45.

9) Menaka M, Pandey VP, Anton Smith A. Formulation Development and Evaluation of Ondansetron Hydrochloride Nasal Spray. International Journal of Pharmacy and Pharmaceutical Sciences. 2013;5(4):150-154.

10) Kahkashan Zaidi. USP Monograph of Xylometazoline nasal solution. USA. 2007;28(3):795.

11) Indian Pharmacopoeia. The controller of publication. 4th edn. New Delhi. 1996;27:736. 
12) Michael I, woke Ug, Remigius U, et al. Nasal Mucoadhesive drug delivery system; background applications, trends and future perspectives. Adv drug Del Rev. 2005;57(11):1641-1660.

13) Menaka M, Pandey VP. Formulation Development and Evaluation of Cinnarizine Nasal Spray. International Journal of Pharma Researxh and Health Sciences. 2014;2(4):339-346.

14) Patil VB, Kalkotwar RS, Patel Ankita, et al. Evaluation and Quality Control of Nasal Spray. Journal of Drug Delivery \& Therapeutics. 2012;2(4):1-4.

15) Guidance for Industry: Nasal spray and inhalation solution, suspension and spray drug products-Chemistry, Manufacturing and Controls. Food and Drug Administration Center for Drug Evaluation and Research. 2002:1-40.

16) Guideline on the pharmaceutical quality of inhalation and nasal Products. EMEA; 2006.

17) Swati P, Ganesh R, Ganesh B. Ex vivo permeation characteristics of venlafaxine through sheep nasal mucosa. European Journal of Pharmaceutical Sciences. 2013;48(2):195-201.
18) Shivhare UD, Jain KZB, Mathur VB, et al. Formulation Development and Evaluation of Diclofenac Sodium Gel Using Water Soluble Polyacrylamide Polymer. Digest Journal of Nanomaterials and Biostructures. 2009;4(2):285-290.

19) Suria $P K$, Ramakrishna Ch, Srivani M, et al. Comparative in vitro release of diclofenac sodium gel from different marketed products. International Journal of Life Science and Pharma Research. 2012;2(3):88-93.

20) Swapnil SC, Mohmed HG. Quality by design approach for development of suspension nasal spray products: a case study on budesonide nasal suspension. Drug Development and Industrial Pharmacy. 2016;42(10):1643-1652.

21) Unites States Pharmacopoeis. Microbiological Tests $/\langle 71\rangle$ Sterility Tests. Rockville, Maryland, USA. pp 2508.

22) Stability testing of New drug substances and products Q1A (R2). European Medicines Agency; 2003.

23) Eskandar M, Abdulghani A, Somayeh H. Absorption-Enhancing Effects of Bile Salts. Molecules. 2015;20(8):14451-14473. 